\title{
A NEW METHOD OF PHOTOGRAPHIC* SPECTRO-PHOTOMETRY.
}

By Toshio Abe, Member.

\section{寫畚分光測光法の新法}

\author{
正會員安一部俊夫 \\ 内 容 梗 概

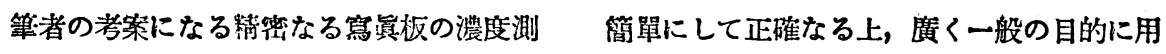 \\ 定法を述ぶっ他の種々なる方法に比し非常にひ得。
}

\begin{abstract}
.
A new apparatus for photographic spectrophotometry is described. It is quite easy in construction and employment,

and may be used so far as the photographic record is made, with the highest degree of accuracy.
\end{abstract}

The precent apparatus is a density meter for phothgraphic plate registering automatically with a wedge, and the intensity is determined from the density according to the ordinary method.

The apparatus is similar to the microphotometer in measuring the density of the very small areas of a photographic plate, but it is not provided with the microscopic objective and though it is an automatic registering type, it is so indifferent to external disturbances that, when in use, it does not need any special supervision. It is rather similar to the Merton's wedge method than the microphotometer in the automatic production of the records using a neutral wedge. But this wedge may be used so far as the photographic record of the spectrum is made without the trouble of preparation and calibration in the ease of the Merton's platinum wedge.(1) And moreover its accuracy is within one or two per cent which in the limit of accuracy of a photographic plate due to the unevenness in sensitivity over its surface.

The principle of this apparatus is shown in the diagram fig. 1 . It is a vertical section of the apparatus. The light from a tungsten arc lamp $O$ is made parallel by

(1) Merton, Roy. Soc., Proc. 106 (1624) 378.

* 到着月日 6 月 1 日 
Fig. 1

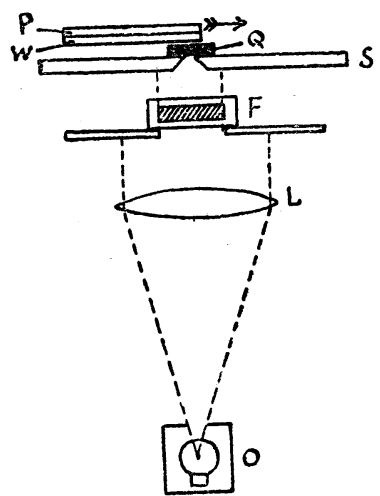

Fig. 2

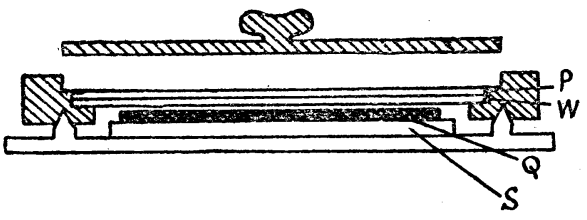

a large convex lens $\mathrm{L}$, and by the filter $\mathrm{F}$ of aqueous solution of cubric chloride, only the wave-length below $5500 \mathrm{~A}$ is transmitted, and illuminates the slit $\mathrm{S}$ uniformly throughout its length. On the upper side of the slit and along its length, a photographic record $Q$ of the spectrum, the density of which is to be measured, is fixed, emulsion side down. Close to $Q$ and above it a brass frame, holding the Goldberg's wedge - it consists of a wedge of gelatine containing carbon in a finely divided state and its method of preparation is fully described in his paper-(2) $\mathrm{W}$, and a photographic plate $\mathrm{P}$, one upon another, is shifted slowly and uniformly on a rail by a D.C. shunt motor and a reducing pulley (fig, 2 ).

On developing and fixing the photographic plate $\mathbf{P}$, a somewhat indistinct curved line is obtained, its abscissae indicating different places on the plate $Q$, and its otdinates giving the degree of density at these places. As it is a difficult matter to locate on the plate the exact position of the curve the plate is immersed for a short time after it has been fully developed and fived, in a "cutting solution" of dilute potassium ferricyanide and again fixed. This treatment should completely remove the slight veil or "chemical fog" which covers the plate, and if the process has been carried until the background is perfectly clear when examined with oblique illumination, the position of the curve is so sharply defined that it can be measured under a micrometer with an accuracy of a hundredth of a millimeter.

As the plate $P$, the Ilford process plate which is not sensitive above wave-lengtn $5500 \mathrm{~A}$ is used. The light employed is, therefore, between the wave-length from 4500 A to 5500 A where the Goldberg wedge holds its neutrality exactly.(3) Hence the co- 
efficient of extinction or the change in the logatithm of the intensity per unit thickness of the wedge, is constant in thic region of wave-length.

The exact way in which the length of the spectrum line, for example, changes with changing density of $Q$ is found as follows :-

If $I_{0}$ is the intensity of light incident on wedge, and I is the intensity of light emergent at the base of wedge, then, by definition, the density $\mathrm{D}$ of wedge at

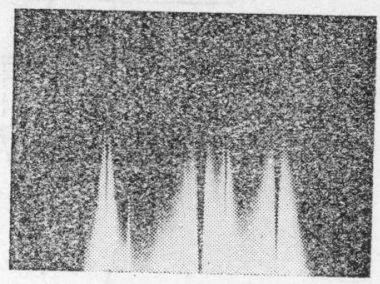
its base, is given by

$$
D=\log _{10} \frac{I_{0}}{I}
$$

But, since absorption by the wedge follows the exponential law,

$$
I=I_{0} 10^{-\zeta x}
$$

where $\zeta$ is the coefficient of extinction and $x$ is the thickness of the gelatine of the wedge. Combining (1) and (2) we have

$$
\begin{aligned}
D & =\log _{10}\left(10^{5 x}\right) \\
& =\zeta x
\end{aligned}
$$

where $x$ is the thickness of base and equal to $\mathrm{AB}$ (fig. 3), that is

$$
D=\zeta A B
$$

Fig. 3

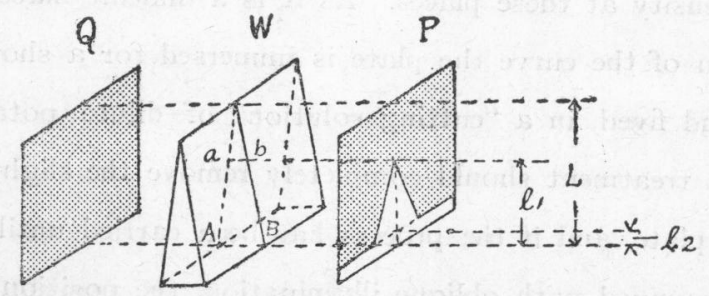

Now, there is a critical exposure of a photographic plate which produces a blackening just visible, and it is the same for all parts of the same plate with the accuracy of one or two per cent. For example, in fig. 3, the critical exposure is that corresponding to the peak, as well as to all parts of the edges of the image of the spectral line. Suppose, therefore (:ee fig. 3) that

$l_{1}$ is the length of spectral line,

$L$ is the length of wedge, 
$I_{1}$ is the intensity of incident light,

$I_{c}$ is the emergent intensity which gives rise to the critical degree of blackening, and

$a b$ is the thickness of wcdge corresponding to the peak of line.

Then by $(2)$

$$
\begin{aligned}
& I_{c}=I_{1} 10^{-\zeta a b} \\
& \text { or } \\
& I_{1}=I_{c} 10^{5 a b} \quad \text { since } \frac{a b}{A B}=\frac{l_{1}}{L} \\
& =I_{c} 10^{\frac{\zeta l_{1} A B}{L}} \\
& =I_{c} 10^{\frac{D l_{1}}{L}} \quad \text { from }(3) \\
& =I_{c} 10^{D l_{1}}
\end{aligned}
$$

where $d$ is the change in density of wedge per unit length on its plate. Suppose, now, the background of $Q$ gives a length $l_{2}$ on the plate $P$, then

$$
I_{2}=I_{c} 10^{d l_{2}}
$$

Combining (4) and (5), we have

$$
\frac{I_{1}}{I_{2}}=10^{\alpha\left(l_{2}-l_{1}\right)}
$$

Then the density of the plate $Q$ at this point is

$$
\log _{10}-I_{2}-=d\left(l_{1}-l_{2}\right)
$$

The value of $d$ is determined easily by a microphotometer of Hartmann's type taking only one value at the base of the wedge using the light of wave-length from $4500 \mathrm{~A}$ to $5500 \mathrm{~A}$. 